Out of 84 patients with colitis who received only medical treatment at St Mark's Hospital, London, ${ }^{11}$ a quarter had reduced social and leisure capacity and 15 reduced earning capacity. The lack of a control group makes it impossible to explain the apparent discrepancy from our results, but the percentage of seriously ill patients was higher at St Mark's.

The active attitude to surgery in our department, which considers a bad "quality of life" as an indication for surgery, has naturally influenced our results. We have no wish to minimise the inconvenience of this serious disease, but with optimal treatment, whether medical or surgical, patients with ulcerative colitis seem to adapt themselves very well to their chronic disease.

\section{References}

${ }^{1}$ Bonnevie O, Binder V, Anthonisen P, Riis P. The prognosis of ulcerative colitis. Scand 7 Gastroent 1974;9:81-91.

2 Anthonisen P, Riis P. Eosinophilic granulocytes in the rectal mucus of patients with ulcerative colitis and Crohn's disease of the ileum and colon. Scand 7 Gastroent 1971;6:731-4.

${ }^{3}$ Riis $\mathrm{P}$, Anthonisen $\mathrm{P}$. The differential diagnosis between ulcerative colitis and Crohn's disease of the colon. Gregor O, Riedl O, eds. 8th International Congress of Gastroenterology, Prague, 1968. Stuttgart, New York: Fk Schattauer Vertag, 1969: 912-3.

${ }^{4}$ Hansen EJ. The distribution of living conditions. Part I. Copenhagen: Danish National Institute of Social Research, 1978. (Publication 82.)

${ }^{5}$ Ronnevie O. A socio-economic study of patients with ulcerative colitis. Scand $\mathcal{F}$ Gastroent 1967;2:129-36.

6 Samuelsson S-M. Ulcerös kolit ock proktit. Uppsala, Socialmedicinska Institutionen, Uppsala Universitet, 1976.

7 Monk M, Mendeloff AI, Siegel CI, Lilienfeld A. An epidemiological study of ulcerative colitis and regional enteritis among adults in Baltimore. II. Social and demographic factors. Gastroenterology 1969; $56: 847-57$.

${ }^{8}$ Binder V, Weeke E, Olsen JH, Anthonisen P, Riis P. A genetic study of ulcerative colitis. Scand $\mathcal{F}$ Gastroent 1966;1:49-56.

9 Lewkonia RM, McConnell RB. Familial inflammatory bowel diseaseheredity or environment ? Gut 1976;17:235-43.

${ }^{10}$ Kirsner JB. Genetic aspects of inflammatory bowel disease. Clinics in Gastroenterology 1973;2:557-75.

${ }^{11}$ Mallett SJ, Lennard-Jones JE, Bingley J, Gilon E. Colitis. Lancet 1978; ii :619-21.

(Accepted 24 June 1980)

\title{
Increased incidence of faecal Klebsiella pneumoniae in patients with HLA B7 CREG antigen and men with rheumatoid arthritis
}

\author{
ROLAND EBRINGER， DIANE COLTHORPE, ADAM YOUNG, MARY CORBETT
}

\section{Summary and conclusions}

In a study of the carriage of faecal Klebsiella pneumoniae in 106 patients with rheumatoid arthritis the incidence of carriage was higher in men $(28 \%)$ than women $(14 \%)$ $(p<0.001)$ and klebsiellae were isolated on two or more occasions from a higher proportion of men than women $(p<0.002)$. The incidence of carriage was increased among patients with rheumatoid arthritis who had $B 7$ cross-reacting (B7 CREG) antigens (32\% v $13 \%$ $\mathrm{p}<0.001)$. Carriage of klebsiellae was not associated with clinical disease activity, raised erythrocyte sedimentation rate, drug treatment, or the presence of HLA Dw4 or DRw4 or both.

Thus the carriage and prevalence of faecal Klebsiella pneumoniae appear to be partly determined by the sex and HLA state of the host.

\section{Introduction}

Evidence exists of cross-reactivity between antigens of the Gram-negative bacillus Klebsiella pneumoniae and lymphocytes positive for HLA B27 in ankylosing spondylitis. ${ }^{1-3}$ We showed that patients with active disease ${ }^{4}$ and acute anterior uveitis in ankylosing spondylitis ${ }^{5}$ have a higher incidence of faecal carriage of klebsiellae than controls or patients with inactive disease. Other investigators confirmed that carriage of faecal $\mathrm{Kl}$ aerogenes

\footnotetext{
Department of Rheumatology, Middlesex Hospital, London W1P 9PG

ROLAND EBRINGER, MRCP, Matilda Poole clinical fellow DIANE COLTHORPE, FIMLS, medical laboratory scientist ADAM YOUNG, MRCP, senior registrar

MARY CORBETT, FRCP, consultant rheumatologist
}

is strongly associated with acute anterior uveitis and peripheral synovitis in ankylosing spondylitis. ${ }^{6}$ Another group was unable to confirm these findings. ${ }^{7}$ Raised erythrocyte sedimentation rates, concentrations of C-reactive protein, and pain scores and increased consumption of anti-inflammatory drugs are also all independently associated with more active disease and with increased incidence of klebsiellae in faecal cultures (unpublished observations). ${ }^{8}$

These findings led to the hypothesis that klebsiella infection may lead to episodes or exacerbations of spinal, peripheral joint, or ocular inflammation in patients with ankylosing spondylitis. An alternative explanation is that the differences in incidence are the result of inflammatory disease rather than its cause and could therefore occur in other inflammatory rheumatic conditions such as rheumatoid arthritis, or that anti-inflammatory drugs may change the incidence of carriage of klebsiella. To examine these possibilities we followed up over three years a group of patients with rheumatoid arthritis. We aimed at determining the incidence of faecal carriage of $\mathrm{Kl}$ pneumoniae and other Gramnegative bacteria associated with postinfectious arthritis in a control population of patients with rheumatoid arthritis, and we compared these results with our reported findings in patients with ankylosing spondylitis.

\section{Patients and methods}

Patient selection-The patients were some of those in a long-term prospective study of early rheumatoid arthritis. ${ }^{9}$ Patients enter this study within the first 12 months of onset of arthritis and are initially followed up at four-monthly intervals. Most patients have definite or classical rheumatoid arthritis according to the criteria of the American Rheumatism Association. ${ }^{10}$ All patients attending the clinic were invited to participate. Sterile collection containers were posted to the patients and a fresh faecal sample collected at the time of the visit. Joint disease activity was divided into three categories and assessed as highly active, moderately active, or inactive. The assessment was 
carried out at the time of examination, before the results of the laboratory examinations were known. This scale rating disease activity correlates well with radiographic progression of disease and articular index. ${ }^{11}$

Bacteriology-Faecal samples were coded and the samples cultured by the methods described previously to isolate Klebsiella and Enterobacter spp and Yersinia enterocolitica. ${ }^{4}$ From July 1977 samples were also cultured on DCA medium and overnight in Selenite F broth to isolate Salmonella and Shigella spp.

Tissue typing-Lymphocytes from patients were typed for HLA A, $\mathrm{B}, \mathrm{C}$, and $\mathrm{D}$ locus antigens by the London Hospital tissue immunology unit.

\section{Results}

We studied 106 patients (64 women) attending the clinic during the study of rheumatoid arthritis from July 1976 to July 1979. Cultures of faecal specimens obtained on 445 patient visits were available for analysis. The minimum interval between consecutive examinations in any patient was four months. The maximum number of cultures obtained from a patient was eight and the average three. Salmonella, Shigella, and $Y$ enterocolitica were not isolated. Only three of the organisms isolated were identified as Enterobacter spp, the rest being $K l$ pneumoniae. Eighty-seven of the 445 samples were positive $(19.5 \%)$.

Forty-nine of the 178 cultures from men $(28 \%)$ were positive for klebsiella as compared with 38 of the 267 from women (14\%). This increase was significant $\left(\chi^{2}=12.004, \mathrm{p}<0.001\right)$. A higher proportion of men compared with women yielded cultures positive for klebsiella on at least one occasion $(57 \% v 39 \%)$, but this was not significant. Thirteen out of 33 men (39\%) were positive on two or more occasions compared with six out of 58 women $(10 \%)\left(x^{2}=10 \cdot 74, \mathrm{p}<0.002\right)$. Cultures were positive on three or more occasions in only two women: one woman was positive for HLA B7 and the other worked in a public health laboratory and had had several uncommon micro-organisms isolated from her faeces including $\mathrm{Kl}$ ozaenae and (after the end of the study) $Y$ enterocolitica. Possibly this patient acquired these microorganisms from her working environment.

Relation of activity of rheumatoid arthritis to faecal carriage of klebsiellae-There was no difference in the incidence of isolation of faecal klebsiellae between patients with active disease $(22 \%)$, moderately active disease $(17 \%)$, and inactive disease $(19 \%)$. Patients with active or moderately active disease were almost invariably receiving anti-inflammatory drugs or a major disease-modifying drug such as gold or penicillamine, or both. Patients with inactive disease were usually receiving no medication.

Relation between erythrocyte sedimentation rate and faecal carriage of klebsiellae-The mean erythrocyte sedimentation rate was $18.43 \mathrm{~mm}$ in the first hour in men and $25.79 \mathrm{~mm}$ in the first hour in women. There was no significant difference in erythrocyte sedimentation rate in men and women between patients with faecal cultures positive and negative for klebsiellae.

Relation between presence of Dw4 or DRw4 antigen and faecal carriage of klebsiellae-Forty-six out of 73 patients $(63 \%)$ tissue typed for the D-locus antigens were positive for HLA Dw4 or DRw4, or both. There was no significant difference in the incidence of faecal carriage of $\mathrm{Kl}$ pneumoniae between patients positive and negative for Dw4 or DRw4 by the first culture obtained or all cultures combined, or, if at least one culture was positive, at any time in one particular patient.

Relation between HLA B7 CREG antigen and carriage of $\mathrm{Kl}$ pneumoniae-Sixty-four patients were tissue typed at the A and B loci. The patients were divided into two groups, one comprising those having HLA B7 cross-reacting antigens B7 CREG (16 patients) and the other comprising the remainder. The antigens included in the serologically overlapping B7 CREG group are HLA B7, Bw22, and B27.12 Twenty-four out of the 74 cultures $\left(32^{\circ}{ }_{0}\right)$ in patients positive for B7 CREG were positive for klebsiellae as compared with 29 out of the 215 cultures $\left(13^{\circ}\right)$ in patients negative for this antigen $\left(\%^{2}=13 \cdot 2\right.$, $\mathrm{p}<0.001)$.

Faecal carriage of klebsiellae in patients positive for HLA B27-Five out of 64 patients $\left(8^{\circ}\right)$ were positive for HLA B27. This incidence is comparable with that found in the general population. Only one out of 19 cultures from these patients was positive for Kl pneumoniae. Of the five patients, only one had definite seropositive symmetrical rheumatoid arthritis. The four others had an atypical, seronegative polyarthritis that had burnt out and become quiescent. One patient had had urethritis with ocular inflammation, which incidentally produced the only culture positive for klebsiella in this group. Another patient who initially presented with seronegative polyarthritis subsequently developed definite but inactive psoriatic spondylarthritis.

\section{Discussion}

These investigations were carried out as a control study to compare the incidence of faecal carriage of $\mathrm{Kl}$ pneumoniae and other potentially arthritogenic Gram-negative micro-organisms in patients with rheumatoid arthritis with our published results obtained in patients with ankylosing spondylitis. There is no evidence to suggest that carriage of klebsiellae in rheumatoid arthritis is associated with clinically active disease, raised erythrocyte sedimentation rate, or the presence of HLA Dw4 or DRw4 antigens, or is altered by treatment with anti-inflammatory drugs. Thus the increased incidence of klebsiella reported in active disease and acute anterior uveitis in ankylosing spondylitis is unlikely to be due to inflammatory disease per se or to antiinflammatory drugs altering bowel flora.

The incidence of carriage of klebsiellae in patients with rheumatoid arthritis $(19.5 \%)$ was lower than the overall incidence found in patients with ankylosing spondylitis $(29 \%)^{13}$ This discrepancy is probably accounted for by the fact that most patients with ankylosing spondylitis are men, as the incidence of carriage in the men with rheumatoid arthritis $(28 \%)$ was comparable with the overall incidence in the patients with ankylosing spondylitis. The $14 \%$ incidence found in women with rheumatoid arthritis compares well with the $10 \%$ obtained in 50 healthy female physiotherapy students seen on their first day of contact with a hospital environment. ${ }^{5}$

We cannot explain the striking difference in the incidence of carriage of klebsiellae between men and women in this study or why chronic carriers of klebsiellae were predominantly men. Although it is premature to speculate on the incidence of carriage in the general population, it is tempting to suggest that there is a predisposing sex-linked factor enhancing carriage of klebsiellae in men as this may conveniently explain the appreciable predominance of men among patients with clinical ankylosing spondylitis and some of the B27 spondylarthropathies. This hypothesis should be tested.

The overall incidence of carriage of klebsiellae in patients with rheumatoid arthritis was lower than that in our hospitalassociated controls $(33 \%),{ }^{5}$ but carriage of faecal klebsiellae is increased in hospital staff. ${ }^{14}$

The second striking observation was the higher proportion of patients positive for B7 CREG carrying klebsiellae. We deliberately chose to examine this HLA cluster because of the mounting evidence that patients with B27-negative ankylosing spondylitis have an increased incidence of B7 CREG antigens. ${ }^{15-18}$ The association of ankylosing spondylitis with several HLA antigens that overlap serologically favours the suggestion that susceptibility to ankylosing spondylitis depends on a common antigenic structure on the HLA molecule rather than a linked gene. ${ }^{19}$ The evidence from the control study of rheumatoid arthritis suggests that, although Klebsiella plays no part in the pathogenesis of rheumatoid arthritis, carriage, recurrence, and persistence of this micro-organism in the gastrointestinal tract are partly determined by the host's histocompatibility antigens.

One possible hypothesis to explain this phenomenon is that the cross-reactivity between klebsiella antigens and HLA B27 lymphocytes may extend to the serologically overlapping B7 CREG antigens. Micro-organisms with some antigenic resemblance to B27 or B7 CREG may be allowed to persist in the gastrointestinal tract of patients positive for B7 CREG. To our knowledge these observations are the first evidence that the carriage of enteric micro-organisms may be partly determined by the sex and HLA state of the host.

We are grateful to Dr A C Boyle, director of the department of rheumatology, for his support; Professor H Festenstein and the staff of the London Hospital tissue immunology laboratory for tissue 
typing the patients; and Mary Slattery for typing the manuscript. The study was supported by grants from the Arthritis and Rheumatism Council.

\section{References}

1 Ebringer A, Cowling P, Suh NN, James DCO, Ebringer RW. Crossreactivity between Klebsiella aerogenes species and B27 lymphocyte antigens as an aetiological factor in ankylosing spondylitis. In: Dausset $\mathrm{J}$, Svejgaard $\mathrm{A}$, eds. $H L A$ and disease. Paris: Institut de la Santé et Recherche Médical, 1976:27 (abstract).

2 Seager K, Bashir HV, Geczy AF, Edmonds J, De Vere-Tyndall A. Evidence for a specific B27 associated cell surface marker on lymphocytes of patients with ankylosing spondylitis. Nature 1979;277:68-70.

3 Welsh J, Avakian H, Cowling P, et al. Ankylosing spondylitis, HLA-B27 and Klebsiella. I. Crossreactivity studies with rabbit antisera. $\mathrm{Br} \mathcal{F}$ Exp Pathol 1980;61:85-91.

4 Ebringer RW, Cawdell DR, Cowling P, Ebringer A. Sequential studies in ankylosing spondylitis: association of Klebsiella pneumoniae with active disease. Ann Rheum Dis 1978;37:146-51.

5 'Ebringer R, Cawdell D, Ebringer A. Klebsiella pneumoniae and acute anterior uveitis in ankylosing spondylitis. $\mathrm{Br}$ Med $\mathcal{F} 1979 ; \mathrm{i}: 383$.

- Eastmond CJ, Willshaw HE, Burgess SEP, Shinebaum R, Cooke EM, Wright V. Frequency of faecal Klebsiella aerogenes in patients with ankylosing spondylitis and controls with respect to individual features of the disease. Ann Rheum Dis 1980;39:118-23.

${ }^{7}$ Warren RE, Brewerton DA. Faecal carriage of Klebsiella in patients with ankylosing spondylitis and rheumatoid arthritis. Ann Rheum Dis 1980; 39:37-44.

${ }^{8}$ Cowling P, Ebringer R, Cawdell D, Ishii M, Ebringer A. C-reactive protein, ESR and Klebsiella in ankylosing spondylitis. Ann Rheum Dis $1980 ; 39: 45-9$.

${ }^{9}$ Fleming A, Crown J, Corbett M. Early rheumatoid disease. I. Onset. Ann Rheum Dis 1976;35:357-60.

10 American Rheumatism Association. Diagnostic criteria for rheumatoid arthritis: 1958 revision. Ann Rheum Dis 1959;18:49-53.

11 Young A, Corbett M, Brook A. The clinical assessment of joint inflammatory activity in rheumatoid arthritis related to radiological progression. Rheumatol Rehabil 1980;19:217-22.

12 Joysey VC, Wolf E. HLA-A, B and C antigens and their serology and crossreactions. $\mathrm{Br}$ Med Bull 1978;34:217-22.

${ }^{13}$ Ebringer R, Cawdell D, Ebringer A. Klebsiella pneumoniae and active inflammatory episodes in ankylosing spondylitis (AS). Ninth European congress of rheumatology, Wiesbaden. Wiesbaden: European League against Rheumatism, 1979:274 (abstract).

14 Seldon R, Lee S, Wang WLL, Bennet JV, Eickhoff TC. Nosocomial Klebsiella infections: intestinal colonization as a reservoir. Ann Intern Med $1971 ; 74: 657-64$.

${ }^{15}$ Arnett FC, Hochberg MC, Bias WB. Crossreactive HLA antigens in B27 negative Reiter's syndrome and sacroiliitis. fohns Hopkins Med f 1977; 141:193-7.

${ }^{16}$ Khan MA, Kushner I, Braun WE. A subgroup of ankylosing spondylitis associated with HLA B7 in American blacks. Arthritis Rheum 1978;21: 528-30.

${ }^{17}$ Säfwenberg J, Domeij-Nyberg B, Kjällman M. HLA antigens in females with ankylosing spondylitis and other forms of seronegative rheumatic diseases. Scand $\mathcal{F}$ Rheumatol 1978;7:177-82.

18 McLain DA, Luehrman LK, Rodey GE, Schwartz BD. An HLA public antigen is more common than HLA-B27 in patients with ankylosing spondylitis. Arthritis Rheum 1980;23:718 (abstract).

10 Ebringer A. Ankylosing spondylitis, immune response genes and molecular mimicry. Lancet 1979 ;ii :1186.

(Accepted 4 fuly 1980)

\section{Androgen production in a patient with Klinefelter's syndrome and choriocarcinoma}

An association has been reported between extratesticular choriocarcinoma and Klinefelter's syndrome, ${ }^{1}$ and the occurrence of a tumour secreting human chorionic gonadotrophin (HCG) has allowed us to study the effects of long-term HCG stimulation on the $\mathrm{XXY}$ aneuploid testis.

\section{Case report}

A 19-year-old sawmill worker developed a cough and haemoptysis. His shaving frequency, up to then twice weekly, became daily. His family had noticed increased hirsutism and weight loss during the preceding three months. A chest radiograph showed multiple nodular lesions $1-5 \mathrm{~cm}$ in diameter in both lung fields, and he required ventilation within 24 hours of admission to hospital. On examination there was striking hirsuties, smooth firm testes ( $2 \mathrm{ml}$ each), a normal sized penis with hypospadias, and gynaecomastia. His arm span was $180 \mathrm{~cm}$ and crown-heel height $168 \mathrm{~cm}$. A karyotype confirmed Klinefelter's syndrome; $47 \mathrm{XXY}$ in all cells. An open-lung biopsy led to the diagnosis of disseminated choriocarcinoma, primary site unknown, and he was given an initial bolus comprising actinomycin C $1 \mathrm{mg}$, cyclophosphamide $1.5 \mathrm{~g}$, adriamycin $40 \mathrm{mg}$, and vincristine $2 \mathrm{mg}$, then two weeks later a three-day course of cis-platinum $20 \mathrm{mg}$ and VP 16-213 $200 \mathrm{mg}$. He made a slow but sustained recovery with intermittent treatment with cisplatinum and VP 16-213 despite an intracranial metastasis, which was successfully treated with intrathecal methotrexate and surgical removal.

On admission his serum albumin concentration was $29 \mathrm{~g} / 1$ and total protein concentration $55 \mathrm{~g} / 1$. The initial HCG concentration (detected also as luteinising hormone) was $106211 \mathrm{mIU} / 1$. The follicle stimulating hormone (FSH) concentration was $2.7 \mathrm{U} / 1$ (normally $<7.0 \mathrm{U} / 1$ ); after $100 \mu \mathrm{g}$ luteinising hormone releasing hormone (LHRH) was given the values were $3.0 \mathrm{U} / 1$ after half an hour, $2.7 \mathrm{U} / 1$ after one hour, and $2.6 \mathrm{U} / 1$ after two hours. The $8 \mathrm{am}$ plasma cortisol concentration was $488 \mathrm{nmol} / 1(17 \cdot 7 \mu \mathrm{g} / 100 \mathrm{ml})$ and the midnight concentration $108 \mathrm{nmol} / 1(3.9 \mu \mathrm{g} / 100 \mathrm{ml})$. Urinary 24 hour total 17-oxosteroids excretion rate was $265 \mu \mathrm{mol} / 24 \mathrm{~h}(76.4 \mathrm{mg} / 24 \mathrm{~h})$ and 17-oxogenic steroids excretion rate $55 \mu \mathrm{mol} / 24 \mathrm{~h}(15.8 \mathrm{mg} / 24 \mathrm{~h})$ Serum oestradiol concentration was under $150 \mu \mathrm{mol} / 1(40.9 \mathrm{ng} / \mathrm{ml}$; normally $50-150 \mu \mathrm{mol} / 1,13 \cdot 6-40.9 \mathrm{ng} / \mathrm{ml}$ ), serum testosterone concentration $11 \cdot 1$ $\mathrm{nmol} / \mathrm{l}(3.2 \mathrm{ng} / \mathrm{ml}$; normally $10.9-33.4 \mathrm{nmol} / \mathrm{l}, \quad 3 \cdot 1-9.6 \mathrm{ng} / \mathrm{ml})$, serum $17 \alpha$-hydroxyprogesterone (17-OHP) concentration $34.0 \mathrm{nmol} / 1(11.3 \mathrm{ng} / \mathrm{ml}$; normally $<15 \mathrm{nmol} / 1,5 \mathrm{ng} / \mathrm{ml}$ ), and serum progesterone concentration $25.9 \mathrm{nmol} / 1(8.1 \mathrm{ng} / \mathrm{ml}$; normally $<0.8 \mathrm{nmol} / 1,0.3 \mathrm{ng} / \mathrm{ml})$. Fourteen days after admission, immediately before treatment with cis-platinum, the HCG concentration was $7386 \mathrm{mIU} / 1,17-O H P$ concentration $18 \mathrm{nmol} / 1(5.9 \mathrm{ng} / \mathrm{ml})$, and testosterone concentration $1.5 \mathrm{nmol} / 1(0.4 \mathrm{ng} / \mathrm{ml})$. Three months after admission HCG concentration had fallen to $20 \mathrm{mIU} / \mathrm{l}$

\section{Comment}

In our patient there was a clear history of recent virilisation with classical Klinefelter habitus. The concentrations of plasma cortisol and excretion rates of urinary oxogenic steroids indicated normal adrenal function; the increased values for urinary oxosteroids and $17-O H P$, the second exclusively of testicular origin, ${ }^{2}$ implied that the hirsutism was secondary to testicular androgen synthesis in response to HCG stimulation. The two other patients with this association of choriocarcinoma and Klinefelter's syndrome were not investigated endocrinologically but in the first, a 16-year-old, there was a normal male escutcheon but no beard growth or gynaecomastia. ${ }^{3}$ The second, a 21-year-old, had gynaecomastia but no hirsutism. ${ }^{1}$

In Klinefelter's syndrome the usual endocrine abnormalities are those of primary hypogonadism with low testosterone concentrations and raised concentrations of gonadotrophins. Although this is thought to be caused by impairment of all steps of testosterone synthesis, a disproportionate increase in the concentration of the precursor steroid 17-OHP in comparison with testosterone concentrations when such patients are given HCG for three days suggests a defect in this conversion. Despite long-term endogenous HCG stimulation in our patient, testosterone concentration was just within the normal range while 17-OHP concentration was over twice normal, as were the values for urinary androgen metabolites. Progesterone concentration was also strikingly raised. There therefore seems to be strong evidence that there is a rate-limiting step in the terminal stages of testosterone synthesis from 17-OHP in patients with Klinefelter's syndrome.

Patients with an HCG-secreting tumour and Klinefelter's syndrome may have a clinical appearance masking their abnormal karyotype, with normal testosterone and suppressed FSH concentrations 